\section{Kidney Blood Pressure Research}

\title{
Evaluation of Mental Disorders Using Proton Magnetic Resonance Spectroscopy in Dialysis and Predialysis Patients
}

\author{
Chun-Yun Zhang ${ }^{\mathrm{a}}$ Ying Chen ${ }^{\mathrm{a}}$ Shan Chen ${ }^{\mathrm{a}} \quad$ Xiang-Chuang Kong ${ }^{\mathrm{b}}$ Yuan Liu ${ }^{\mathrm{b}}$ \\ Chao-Qun You ${ }^{a}$ Cheng Wan ${ }^{a}$ Philip A. Bondzie ${ }^{c} H_{u a} u^{a}$ Chun Zhanga Fang- \\ Fang $\mathrm{He}^{\mathrm{a}}$
}

aDepartment of Nephrology, Union Hospital, Tongji Medical College, Huazhong University of Science and Technology, Wuhan; 'bepartment of Radiology, Union Hospital, Tongji Medical College, Huazhong University of Science and Technology, Wuhan, China; 'Department of Pathology and Laboratory Medicine, Boston Medical Center, Boston University School of Medicine, Boston, Massachusetts, USA

\section{Key Words}

Chronic kidney disease $\bullet$ Mental disorders $•$ Proton magnetic resonance spectroscopy $\bullet$ Dialysis - Brain

\begin{abstract}
Background/Aims: Psychological complications are prevalent in patients with chronic kidney disease (CKD). This study aimed to investigate mental disorders in stage 4-5 CKD patients, to detect metabolite concentrations in the brain by proton magnetic resonance spectroscopy $\left({ }^{1} \mathrm{H}-\mathrm{MRS}\right)$ and to compare the effects of different dialysis therapies on mental disorders in end-stage renal disease (ESRD). Methods: The sample population was made up of predialysis (13), hemodialysis (HD) (13), and peritoneal dialysis (PD) patients (12). We collected the baseline data of patients' age, sex, hemoglobin $(\mathrm{Hb})$ and parathyroid hormone (PTH) levels. The predialysis patients served as the control group. The psychological status of the three groups was assessed using three psychological scales. ${ }^{1} \mathrm{H}-\mathrm{MRS}$ was used to evaluate the relative metabolite concentrations in the bilateral amygdala, hippocampus and unilateral anterior cingulated cortex (ACC). Results: The psychological status was better in HD patients than in predialysis and PD patients. ${ }^{1} \mathrm{H}-\mathrm{MRS}$ alterations were predominantly found in the ACC. Choline-containing compounds relative to creatine $(\mathrm{Cho} / \mathrm{Cr})$, myo-inositol relative to creatine $(\mathrm{MI} / \mathrm{Cr})$ and glutamate and glutamine relative to creatine $(\mathrm{GlX} / \mathrm{Cr})$ in the ACC were higher in HD patients. ${ }^{1} \mathrm{H}$-MRS results were correlated with the baseline data and the scores of psychological scales. Conclusions: CKD patients showed different types of mental disorders as well as metabolite disturbances in the brain. The metabolite concentrations correlated with the psychological status which was better in HD than in predialytic and PD patients.
\end{abstract}

C.-Y. Zhang and Y. Chen are contributed equally to this work,

(C) 2017 The Author(s)

Published by S. Karger AG, Basel

Fang-Fang $\mathrm{He}$

Department of Nephrology, Union Hospital, Tongji Medical College,

Huazhong University of Science and Technology, Wuhan 430022, China

Tel. 86-027-85726805, Fax 86-027-83617730, E-Mail hefang_105@163.com 


\section{Kidney Blood Pressure Research}

\section{Introduction}

Chronic kidney disease (CKD) is a highly prevalent disease with an about $10 \%$ morbidity rate worldwide [1]. The psychological complications associated with CKD contribute greatly to a poor quality of life, cardiovascular diseases, and increased mortality rate. Previous studies reported associations between poor mental health and cardiac death in dialysis patients $[2,3]$. Psychological complications related to CKD are characterized by depression, anxiety, cognitive impairment, fatigue, impaired concentration, memory decline and sleep disturbances. However, these manifestations are usually ignored by clinicians. Depression is one of the most widely acknowledged psychological disorders among CKD patients [4,5]. About $28 \%$ of predialysis patients suffer from major depression and the morbidity is also high in dialysis patients [6]. Another common problem is anxiety, which is inversely proportional to the quality of life [7]. Clinical variables such as age, residual renal function, comorbidities and uremic symptoms are identified to be closely related to anxiety in CKD patients [8]. However, little is understood about the relationship between psychological complications and alterations of metabolites concentrations in specific regions of the brain. Emerging evidence has shown that structural and metabolic alterations in specific brain regions are related to emotional and mental modulation. Increased activation of limbic and paralimbic areas, such as the ACC, hippocampus and amygdala, has been proved to be associated with major depressive disorder $[9,10]$. Neurobiological experiment has demonstrated an excessive activity of the ACC in obsessive compulsive disorder (OCD) patients when making conflicting options [11]. The reward/avoidance circuitry of the basal ganglia and the fear circuitry of the amygdala both play a role in the development of social anxiety disorder [12, 13]. The ACC, as a part of cortical regions, is included in the reward/avoidance basal ganglia circuitry [14]. Hippocampus is known to be involved in mnemonic processes. The dorsal hippocampus has spatial navigational functions and the ventral hippocampus is associated with anxiety and context fear learning $[15,16]$. Taken together, we chose unilateral ACC, bilateral amygdala, and hippocampus as the major brain regions for this study. Proton magnetic resonance spectroscopy ( $\left.{ }^{1} \mathrm{H}-\mathrm{MRS}\right)$, a noninvasive and quantitative technique that utilizes magnetic resonance and chemical shift to determine concentrations of chemicals and macromolecules, has been increasingly applied to investigate metabolites in specific regions of the brain in vivo $[17,18] .{ }^{1} \mathrm{H}-\mathrm{MRS}$ has been used to evaluate metabolites such as $\mathrm{N}$-acetyl Aspartate (NAA), choline-containing compounds (Cho), creatine (Cr), myo-inositol (MI), glutamate and glutamine (Glx) in psychological disorders including depression, anxiety and OCD. Previous studies detected a decreased level of Glx in the anterior brain regions in acute depressed patients $[19,20]$, a decreased MI/Cr ratio in the left orbitofrontal region and an increased concentration of Cho in the left and right thalamic nuclei of OCD patients [21, 22]. However, research on the application of ${ }^{1} \mathrm{H}$-MRS to assess psychological dysfunctions in CKD patients is limited. Therefore, our study aimed to explore the neuropsychological complications in CKD patients with the method of ${ }^{1} \mathrm{H}$-MRS.

\section{Materials and Methods}

\section{Subjects}

We recruited 13 predialysis patients, 13 HD patients and 12 peritoneal dialysis (PD) patients with ages ranging from 27 to 74 years old, from the Union Hospital, Tongji Medical College, Huazhong University of Science and Technology, from July 2015 to September 2016, in this study. Inclusion criteria: (i) 18 to 80 years old inpatients; (ii) Dialysis age over one month or predialysis patients with stage 4-5 CKD; (iii) No cognition-interference factors (color blind, deaf, disabled upper limbs, or poor general condition); (iv) Written informed consent. Exclusion criteria: (i) Diagnosed with intracranial tumor; (ii) Diagnosed with non-atherosclerotic cerebrovascular disease (e.g. vasculitis); (iii) Diagnosed with metabolic encephalopathy such as hepatic encephalopathy and pulmonary encephalopathy; (iv) Diagnosed with 


\section{Kidney \\ Blood Pressure Research}

epilepsy requiring long-term medication; (v) Alcohol or other drugs addiction; (vi) Cardiac pacemakers, other electrodes or magnetic substances implanted or aneurysm clip in vivo or metal foreign bodies in the eye. The study protocol was approved by the Ethics Committee of Huazhong University of Science and Technology. All participants signed consents after detailed explanation of the study. Age, sex, hemoglobin ( $\mathrm{Hb}, \mathrm{g} / \mathrm{L}$ ), parathyroid hormone (PTH, $\mathrm{pg} / \mathrm{ml}$ ) were collected as the baseline data.

\section{Psychological assessments}

Self-Rating Depression Scale (SDS), Self-Rating Anxiety Scale (SAS) [23] and Symptom Checklist 90 (SCL 90) were used to assess the psychological status. According to Chinese norm, total score of SDS can be divided into 4 grades: normal ( $<53$ points), mild depression (53-62 points), moderate depression (63-72 points) and severe depression ( $>72$ points). Total score of SAS can be divided into 4 grades: normal $(<50$ points), mild anxiety (50-59 points), moderate anxiety (60-69 points) and severe anxiety ( $>70$ points). Ten subscales of SCL 90 are F1 Somatizatin, F2 OCD, F3 Interpersonal sensitivity, F4 Depression, F5 Anxiety, F6 Hostility, F7 Phobophobia, F8 Paranoia, F9 Psychopathy, and F10 Others (sleeping and diet). A total score of SCL 90 over 160 points or numbers of positive factors over 43 or any subscale over 2 points is defined as positive.

\section{MRS methodology}

${ }^{1} \mathrm{H}$-MRS was performed on a GE 750W 3.0T scanner with a 16-channel head-neck combined coil after the conventional magnetic resonance imaging examination. The patients laid flat on the examining table with their heads fixed during the scanning. Three-dimensional multi-voxel spectroscopy (Repetition time $=$ $1000 \mathrm{~ms}$, Echo time $=144 \mathrm{~ms}$, Acquisition time $=8 \mathrm{~min}$, voxel $=12 \times 20 \times 20 \mathrm{~mm}$ ) was used for the bilateral amygdala and hippocampus. Single voxel spectroscopy (Repetition time $=1500 \mathrm{~ms}$, Echo time $=35 \mathrm{~ms}$, Acquisition time $=3 \mathrm{~min}$, voxel $=20 \times 20 \times 20 \mathrm{~mm}$ ) was used for the unilateral ACC. A rapid automated shimming method was conducted by the machine. After water suppression and tuning, ${ }^{1} \mathrm{H}-\mathrm{MRS}$ spectra were obtained and directly analyzed by Functool 9.4 .05 software in the GE Medical System.

\section{Statistical analysis}

All data were analyzed by IBM SPSS statistic 22.0. A two-sided probability value of $P<0.05$ was considered as statistically significant. Analysis of variance (ANOVA) followed by Student-Newman-Keuls-q (SNK-q) test was used to analyze the differences between the three groups. Spearman's test was performed for correlation analysis.

\section{Results}

High prevalence of psychological disorders in CKD patients

Depression and anxiety were quite common in our CKD patients. The patients mainly suffered from mild to moderate depression or mild anxiety. The prevalence of depression in predialysis, $\mathrm{HD}$ and $\mathrm{PD}$ patients was $84.62 \%$, $84.62 \%$, and $83.33 \%$ (Fig. $1 \mathrm{~A}$, $1 \mathrm{~B}, 1 \mathrm{C})$, while the prevalence of anxiety was $15.38 \%$, $15.38 \%$, and $58.33 \%$ (Fig. $1 \mathrm{D}, 1 \mathrm{E}, 1 \mathrm{~F})$, respectively.

The total score of SDS $(P=0.58)$ and SAS $(P=$ $0.15)$ was not statistically different between the predialysis, $\mathrm{HD}$ and $\mathrm{PD}$

Table 1. Characteristics of all patients. $\mathrm{HD}=$ hemodialysis; $\mathrm{PD}=$ peritoneal dialysis; $\mathrm{Hb}=$ hemoglobin; $\mathrm{PTH}=$ parathyroid hormone. ${ }^{*} \mathrm{P}<0.05$ Predialysis patients vs. HD patients. ${ }^{* *} \mathrm{P}<0.05$ HD patients vs. PD patients.

\begin{tabular}{lccc}
\hline Baseline data & Predialysis, $\mathrm{n}=13$ & $\mathrm{HD}, \mathrm{n}=13$ & $\mathrm{PD}, \mathrm{n}=12$ \\
\hline Age & & & \\
$\quad$ Range & $27-65$ & $27-64$ & $27-57$ \\
Mean & $41.0 \pm 11.9$ & $51.1 \pm 10.9$ & $42.0 \pm 11.4$ \\
Sex & & & \\
$\quad$ Female & 6 & 5 & 6 \\
$\quad$ Male & & & 6 \\
Hb (g/L) & $66-126$ & $63-128$ & $81-110$ \\
$\quad$ Range & $88.9 \pm 15.4^{*}$ & $107.2 \pm 18.1$ & $94.7 \pm 9.2^{* *}$ \\
$\quad$ Mean & & & \\
PTH (pg/ml) & $52-862$ & $2.7-1230$ & $49.2-1304$ \\
$\quad$ Range & $295.2 \pm 260.1$ & $473.3 \pm 363.2$ & $501.5 \pm 340.4$ \\
$\quad$ Mean & & & \\
\hline
\end{tabular}




\section{Kidney Blood Pressure Research}

patients (data not shown). The positive rate of SCL 90 was $31.58 \%$. The positive items of SCL 90 scale varied from F1 Somatization to F9 Psychopathy. There were significant differences between predialysis and HD patients in F2 OCD $(1.76 \pm 0.16$ vs. $1.26 \pm 0.07$, $P<0.05$ ), F3 Interpersonal sensitivity $(1.54 \pm 0.16 \mathrm{vs}$. $1.18 \pm 0.06, P<0.05)$, F5 Anxiety $(1.56 \pm 0.13 \mathrm{vs}$. $1.22 \pm 0.04, P<0.05), \mathrm{F} 8$ Paranoia $(1.47 \pm 0.14$ vs. $1.09 \pm 0.05, P<0.05)$ and F9 Psychopathy $(1.53 \pm 0.19 v s$. $1.22 \pm 0.06, P<0.05$ ) (Fig. 2), suggesting a relatively less disordered psychological symptoms such as OCD, interpersonal sensitivity, anxiety, paranoia, and psychopathy in HD patients. SCL 90 results between HD and PD patients were not significantly different, although the mean score was lower in HD patients than in PD patients. In addition, the three groups didn't differ in age, sex, and PTH levels. The mean level of $\mathrm{Hb}$ was higher in $\mathrm{HD}$ patients than in predialysis and PD patients $(\mathrm{P}<0.05$, Table1). No correlations between the results of psychological scales and the baseline data (age, sex, Hb and PTH levels) were found (data not shown).

\section{Elevated ratios of Cho/Cr, $\mathrm{MI} / \mathrm{Cr}$ and $\mathrm{Glx} / \mathrm{Cr}$ in the $\mathrm{ACC}$ were found in $\mathrm{HD}$ patients}

Differences of $\mathrm{Cho} / \mathrm{Cr}$ in the ACC mainly existed between predialysis and HD patients $(0.98 \pm 0.06$ vs. $1.14 \pm 0.04, P<0.05)$, as well as between HD and PD patients $(1.14 \pm 0.041$ vs. $0.98 \pm 0.07, P<0.05$ ) (Fig. 3A). Differences of MI/Cr in the ACC mainly existed between predialysis and HD patients $(0.62 \pm 0.02$ vs. $0.68 \pm 0.02, P<0.05)$, as well as between HD and PD patients (0.68 \pm 0.02 vs. $0.60 \pm 0.02, P<0.05$ ) (Fig. 3B). Difference of Glx/Cr in the ACC was found between predialysis and HD patients $(2.64 \pm 0.10 v s .2 .94 \pm 0.09, P<0.05)$ (Fig. $3 \mathrm{C}$ ). In summary, these results suggested higher ratios of $\mathrm{Cho} / \mathrm{Cr}, \mathrm{MI} / \mathrm{Cr}$ and $\mathrm{Glx} / \mathrm{Cr}$ in the ACC in HD patients than in predialysis and PD patients.

Fig. 1. Depression and anxiety are prevalent in CKD patients. Positive rates of SDS in predialysis patients (A), HD patients (B) and PD patients (C). Positive rates of SAS in predialysis patients (D), HD patients (E) and $\mathrm{PD}$ patients (F). HD = hemodialysis; PD = peritoneal dialysis; Data are shown as percentages.

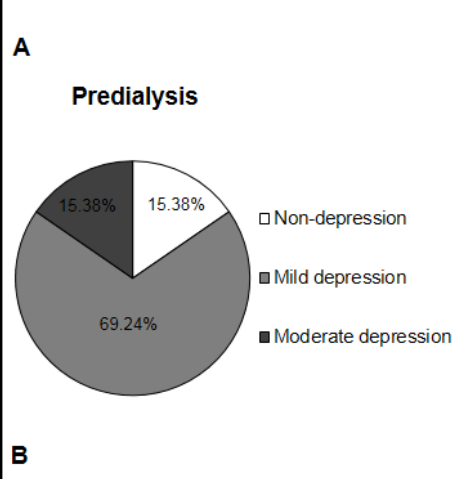

D

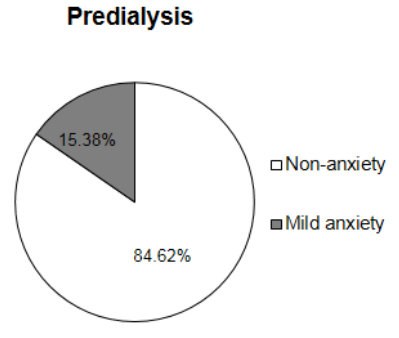

E

C
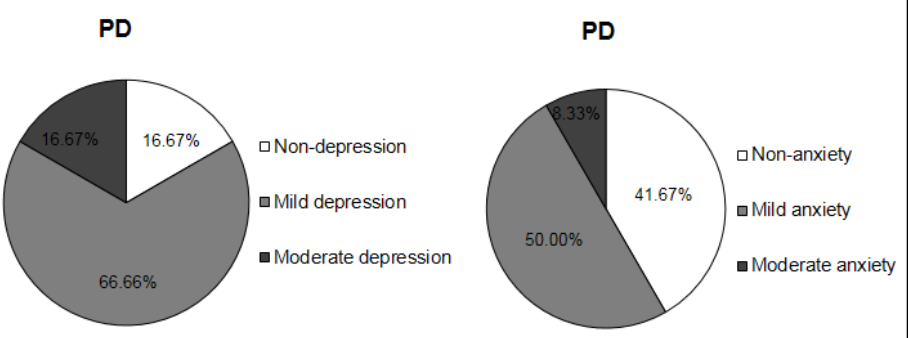

HD
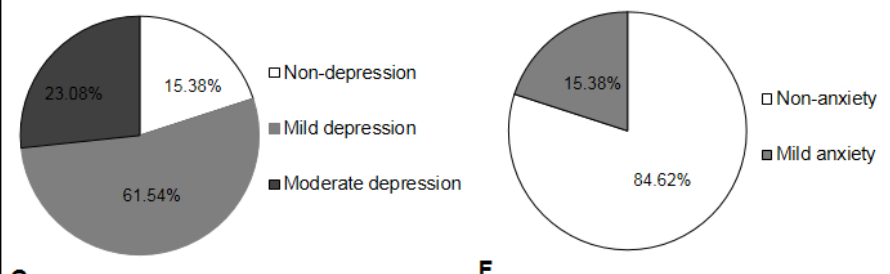

F 


\section{Kidney Blood Pressure Research}

Corre lations between the relative concentrations of metabolites in the brain and the baseline data $\mathrm{MI} / \mathrm{Cr}$ in the right amygdala was positively correlated with age $(r=$ $0.350, P=0.034$ ) (Fig. 4A). NAA/Cr in the left amygdala was positively correlated with $\mathrm{Hb}(r=0.359, P$ $=0.027$ ) (Fig. 4B). No correlations between ${ }^{1} \mathrm{H}$-MRS results and sex or PTH were found (data not shown).

Correlations between the relative concentrations of metabolites in the brain and the scores of psychological scales

$\mathrm{MI} / \mathrm{Cr}$ in the left amygdala was negatively correlated with SDS total score $(r=-0.370, P=$ 0.022 ) (Fig. 5A). Cho/ $\mathrm{Cr}$ in the right amygdala was positively correlated with F2 OCD $(r=0.322, P$ $=0.048)$, F5 Anxiety $(r=$ $0.381, P=0.018)$ and F9 Psychopathy $(r=0.436, P=$ 0.006 ) (Fig. 5B, 5C, 5D).

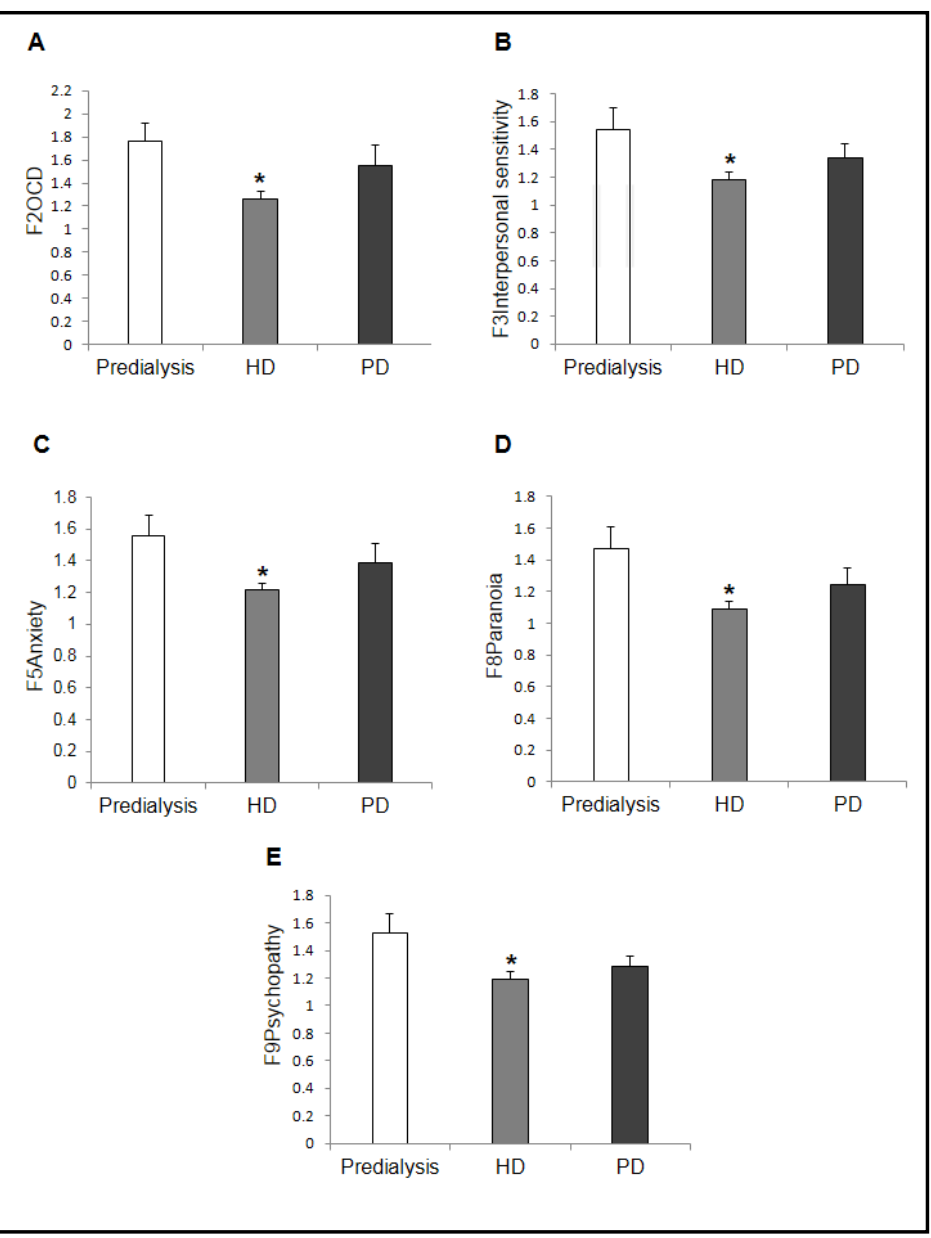

Fig. 2. Positive items of SCL 90 in CKD patients. Significant difference of F2 OCD (A), F3 Interpersonal sensitivity (B), F5 Anxiety (C), F8 Paranoia (D) and F9 Psychopathy (E) between predialysis and HD patients. HD = hemodialysis; OCD = obsessive compulsive disorder; $\mathrm{PD}=$ peritoneal dialysis; Data are presented as means \pm SEM. ${ }^{*} \mathrm{P}<0.05$ Predialysis patients vs. HD patients.

\section{Discussion}

Psychological disorders with the symptoms of depression and anxiety are quite prevalent in CKD patients. Compared to HD patients, predialysis patients suffered more in OCD, interpersonal sensitivity, anxiety, paranoia, and psychopathy. These are consistent with a previous study showed that predialysis patients had high prevalences of depression and anxiety, which were associated with reduced quality of life [24]. Due to the transition state, the fears, uncertainties, and desperation experienced by predialysis patients may explain why they mostly suffer from the mental disorders. These results strongly suggest the necessity of strengthening human concern and psychological counsel to CKD patients, especially predialysis patients.

In our ${ }^{1} \mathrm{H}$-MRS studies, we identified relatively higher levels of $\mathrm{Cho} / \mathrm{Cr}, \mathrm{MI} / \mathrm{Cr}$ and $\mathrm{Glx} / \mathrm{Cr}$ in the ACC in HD patients compared to predialysis and PD patients. Cho, as a cell membrane precursor and breakdown product, contributes to neural membrane synthesis and catabolism [25]. Increase of Cho peak in ${ }^{1} \mathrm{H}-\mathrm{MRS}$ is attributed to accelerated turnover of 


\section{Kidney Blood Pressure Research}

membrane phospholipids or neurodegeneration [26]. Our study may suggest an enhanced membrane turnover and cellular signal transduction in the ACC in HD patients. Similarly, $\mathrm{MI} / \mathrm{Cr}$ in the ACC was elevated in HD patients, as was observed with Cho/Cr. MI, serving as an osmolyte involved in neuronal energy supply, is abundant in glial cells. MI and its related compounds play a significant role in intracellular second messenger transduction, as MI is a key metabolic precursor in the phosphoinoside second messenger cycle. Increased MI suggests glial cells proliferation while decreased MI suggests damage to glial cells or neurodegeneration [27]. Our study finds a better function of glial cells in the ACC in HD patients. Also, an ascending trend of Glx/ $\mathrm{Cr}$ in the ACC in HD patients was found, implying that HD patients might have better functions of excitatory neurotransmitter than predialysis and PD patients in the ACC. Glx refers to glutamate and glutamine. Glutamate is one of the major excitatory neurotransmitters in the brain. Elevated level of $\mathrm{Glx} / \mathrm{Cr}$ in $\mathrm{HD}$ patients may be associated with better glucose metabolism $[28,29]$, which helps to maintain a more stable environment for the brain.

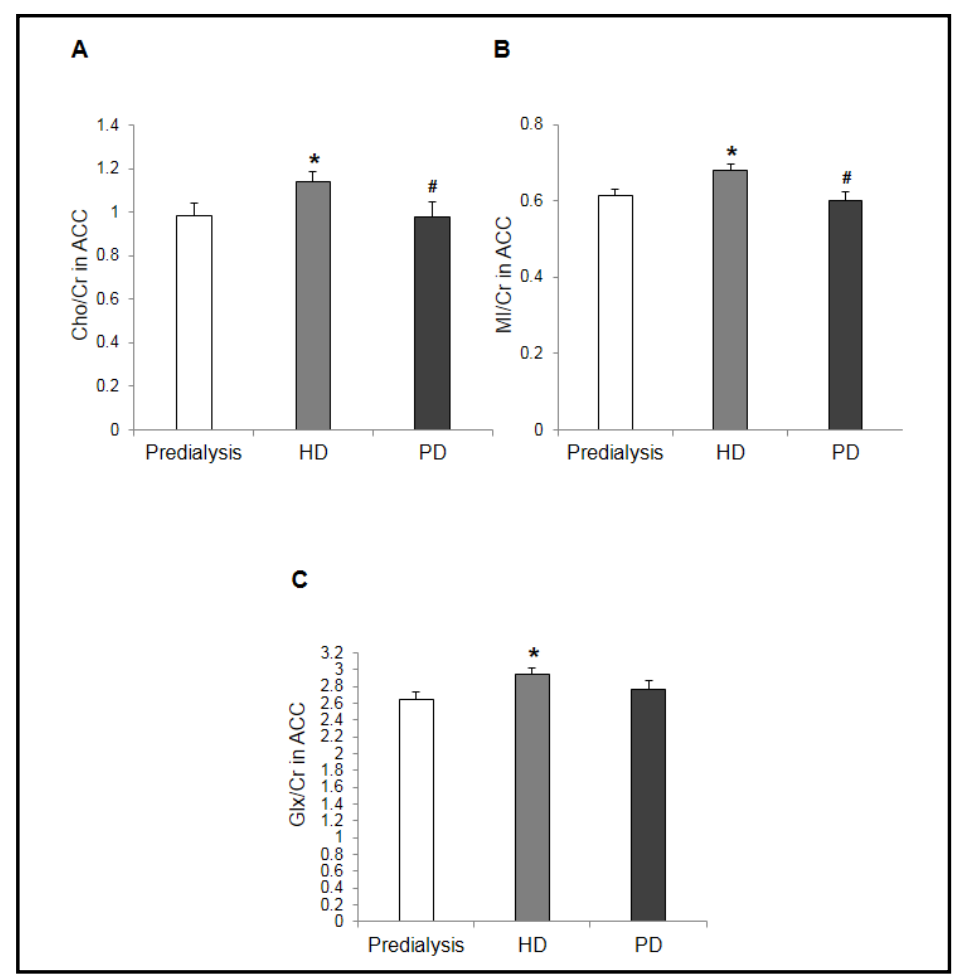

Fig. 3. Elevated ratios of $\mathrm{Cho} / \mathrm{Cr}, \mathrm{MI} / \mathrm{Cr}$, $\mathrm{Glx} / \mathrm{Cr}$ in the $\mathrm{ACC}$ are found in HD patients. Significant difference of $\mathrm{Cho} / \mathrm{Cr}$ in the ACC between predialysis and HD patients, HD and PD patients (A). Significant difference of MI/Cr in the ACC between predialysis and HD patients, HD and PD patients (B). Significant difference of Glx/Cr in the ACC between predialysis and HD patients (C). ACC = anterior cingulated cortex; Cho = choline-containing compounds; $\mathrm{Cr}=$ creatine; $\mathrm{Glx}=$ glutamate and glutamine; $\mathrm{HD}=$ hemodialysis; $\mathrm{MI}=$ myo-inositol; $\mathrm{PD}=$ peritoneal dialysis. Data are presented as means \pm SEM. ${ }^{*} \mathrm{P}<0.05$ Predialysis patients vs. HD patients. $\# \mathrm{P}<0.05$ HD patients vs. PD patients.

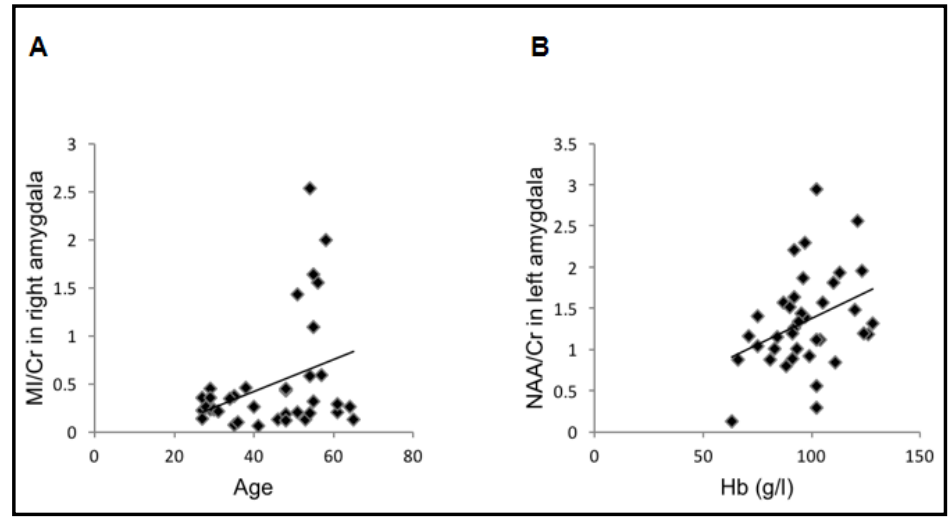

Fig. 4. Relative concentrations of metabolites in the brain are positively correlated with age and $\mathrm{Hb}$. MI/Cr in the right amygdala is positively correlated with age (A). NAA/Cr in the left amygdala is positively correlated with $\mathrm{Hb}(\mathrm{B}) . \mathrm{Cr}=$ creatine; $\mathrm{MI}=$ myo-inositol; $\mathrm{NAA}=\mathrm{N}$-acetyl aspartate; $\mathrm{Hb}=$ hemoglobin. 


\section{Kidney Blood Pressure Research}

Fig. 5. Relative concentrations of metabolites in the brain are correlated with the scores of psychological scales. $\mathrm{MI} / \mathrm{Cr}$ in the left amygdala is negatively correlated with SDS total score (A). Cho/Cr in the right amygdala is positively correlated with F2 OCD (B), F5 Anxiety (C) and F9 Psychopathy (D). Cho = cholinecontaining compound; $\mathrm{Cr}=$ creatine; $\mathrm{MI}=$ myo-inositol; OCD = obsessive compulsive disorder; SDS = Selfrating Depression Scale.
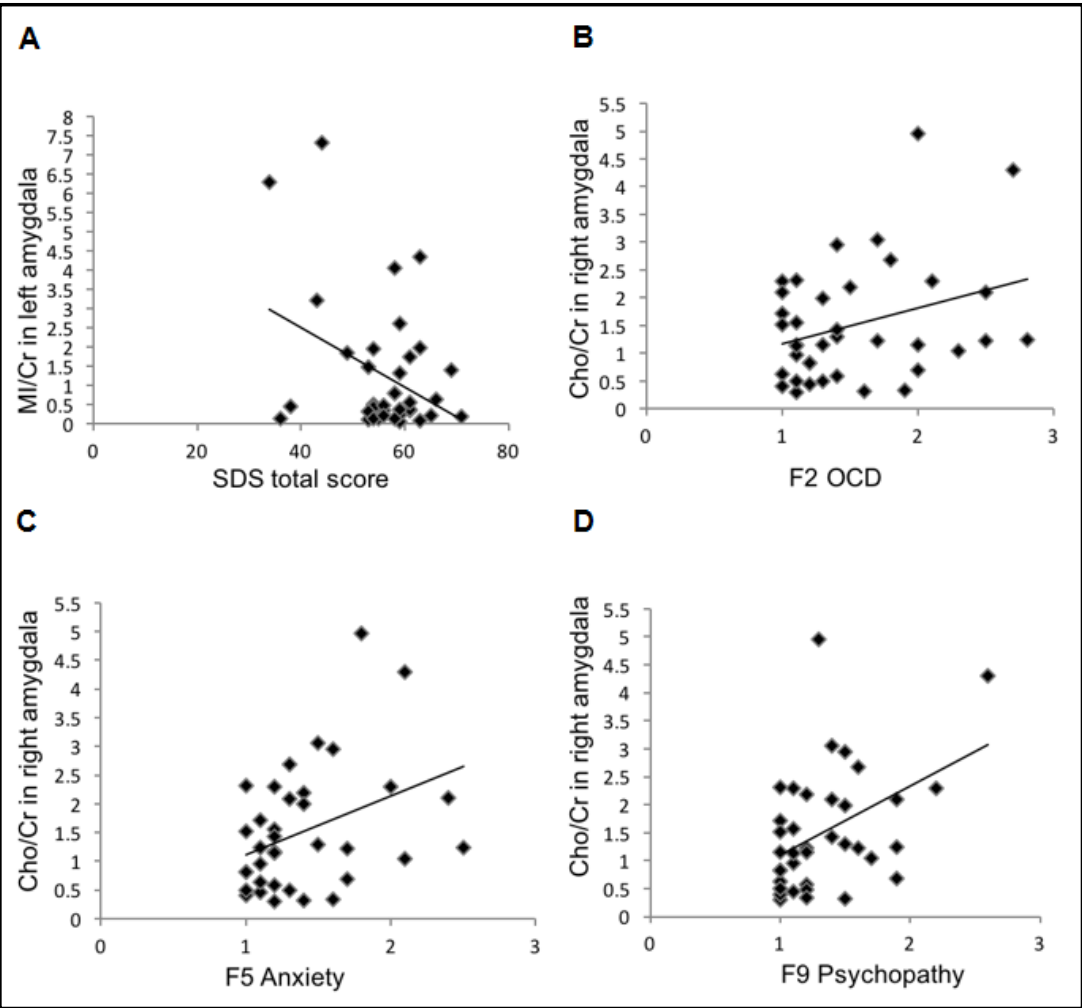

Increasing evidence indicates that mental disorders, such as depression, are associated with dysfunction of the excitatory neurotransmitters glutamate [19].

Besides, $\mathrm{MI} / \mathrm{Cr}$ in the right amygdala was positively correlated with age. Early study reported an increase of $\mathrm{MI} / \mathrm{Cr}$ in mild cognitive impairment [30] and MI/Cr level was associated with dementia stages [31]. Accordantly, previous studies reported cognitive ability declined on an average rate of 0.04 standardized units per year [32]. Variables such as concentrations of brain metabolites, regional brain volume, and cortical thickness were associated with age-related decline of cognition [33, 34]. Based on these data, we conclude that elevated $\mathrm{MI} / \mathrm{Cr}$ might be involved in aging-related cognition impairment.

Furthermore, we found a positive correlation between NAA/Cr in the left amygdala and $\mathrm{Hb}$. NAA has been described as a neuronal marker. An increase of NAA in the left amygdala is considered as a functional enhancement and/or an increased density of neuronal cells [35] or improved osmolytic situations in the neuronal environment [36]. Anemia may affect the function of the brain by injuring neuronal cells. Former studies conducted in HD patients showed that anemia resulted in impaired cognition, and correction of renal anemia with erythropoietin improved not only the quality of life but also cognition and depression [37]. The underlying mechanism might be an enhanced delivery of oxygen to subcortical and frontotemporal brain structures, which are associated with mental disorders [38]. Previous studies found a significant decreased NAA concentration in the left amygdala and bilateral orbito-frontal cortex in the children with autism spectrum disorders, and the level of NAA was correlated with the social quotient of these autistic children. Further, oxygenated-Hb, measured by near-infrared spectroscopy machine, was significantly lower in the same areas of the brain. After imitation of emotional facial expression, the oxygenated-Hb level was elevated [39]. In summary, anemia in CKD patients may result in dysfunction or decreased density of neural cells because of decreased oxygen supply to the brain. In addition, the mean level of $\mathrm{Hb}$ was higher in HD patients than in predialysis and PD patients, which may be attributed to the normatively use of erythropoietin in HD patients. 


\section{Kidney Blood Pressure Research}

Next, we found a negative correlation between MI/Cr in the left amygdala and depression. Similarly, a previous study discovered a relatively lower level of MI/Cr in the frontal white matter in acute depression [40]. Another study found elevated levels of MI and MI/Cr in the ACC in fully recovered depressed patients [41]. Lower MI/Cr may reflect dysfunction of glial cells in the left amygdala in CKD patients with mental disorders. Also, alteration of Cho concentrations in the brain may relate to psychological symptoms. Studies reported that Cho in the left thalamus was significantly correlated with social anxiety and its related symptoms [42]. Elevated levels of Cho were found in the ACC of patients with schizophrenia [43] and in the dorsolateral prefrontal cortex of patients with major depressive disorder [44]. Consistent with previous studies, $\mathrm{Cho} / \mathrm{Cr}$ in the right amygdala was positively correlated with OCD, anxiety and psychopathy in our study, which might suggest a pathophysiological basis of changed $\mathrm{Cho} / \mathrm{Cr}$ in the right amygdala in mental disorders of CKD patients.

It is noteworthy that our study didn't find a significant change of NAA in the amygdala, hippocampus and ACC in CKD patients with psychological disorders. Some studies reported no changes of NAA in depressed patients with antidepressant therapy for several weeks [45, 46], whereas others found an increase of NAA in the dorsolateral prefrontal cortex of the brain after therapy $[47,48]$. Futher studies with a wider range of brain structures and a larger sample size may be needed to obtain a definite answer about the changes of NAA in mental disorders. In addition, we didn't find any association between F4 Depression and changes of metabolites in the brain although depression is quite prevalent in CKD patients. The mean value of F4 Depression was $1.52 \pm 0.55$ whereas the point of a factor over 2 was considered as positive. The depressed symptom assessed by SCL 90 might be so slight that the changes of the metabolite could not be detected by ${ }^{1} \mathrm{H}-\mathrm{MRS}$.

Our study has several limitations: a relatively small sample size was the major limiting problem, as usually has occurred in previous studies. Another limitation was the lack of an age-matched healthy control. The use of the multiple-voxel method enabled accurate localization but limited findings in restricted regions. Also, to obtain a stable baseline, long Echo time in three-dimensional multi-voxel spectroscopy scanning was used, however, it may be inadequate to analyze the data of MI and Glx. In addition, this study could not provide a causal link between psychological symptoms and changes of metabolites. Finally, all the data were presented as the concentrations of metabolites relative to $\mathrm{Cr}$, which were conventional but limited. It is possible that the absolute concentration of $\mathrm{Cr}$ was decreased or increased while the absolute concentrations of other metabolites were unchanged. Future studies may reference the concentrations of metabolites to tissue water to avoid the potential confounding effect of $\mathrm{Cr}$.

\section{Conclusion}

The present study reported the psychological status of predialysis and dialysis patients by combining the psychological scales with ${ }^{1} \mathrm{H}$-MRS technology to elucidate the pathological changes of metabolites in different regions of the brain. HD therapy showed benefits on patients' mental status. Further studies are required for larger samples clarifying the relationship between the mental status and the changes of metabolites in the brain of CKD patients.

\section{Disclosure statement}

The authors declare that there is no Disclosure Statements regarding the publication of this paper. 


\section{Kidney Blood Pressure Research}

\begin{tabular}{l}
\hline Kidney Blood Press Res 2017;42:686-696 \\
\begin{tabular}{l|l}
\hline DOI: 10.1159/000484023 & $\begin{array}{l}\text { (c) 2017 The Author(s). Published by S. Karger AG, Basel } \\
\text { www.karger.com/kbr }\end{array}$ \\
\hline Published online: October 18, 2017
\end{tabular} \\
\hline
\end{tabular}

Zhang et al.: Mental Disorders in Dialysis and Predialysis Patients

\section{Acknowledgements}

This study was supported by grants from the National Natural Science Foundation of China (No.81400720) and National Science \& Technology Pillar Program (2011BAI10B02).

\section{References}

$>1$ Coresh J, Astor BC, Greene T, Eknoyan G, Levey AS: Prevalence of chronic kidney disease and decreased kidney function in the adult US population: Third National Health and Nutrition Examination Survey. Am J Kidney Dis 2003;41:1-12.

- Kang EW, Pike F, Ramer S, Abdel-Kader K, Myaskovsky L, Dew MA, Unruh M: The association of mental health over time with cardiac outcomes in HEMO study patients. Clin J Am Soc Nephrol 2012;7:957-964.

- Untas A, Thumma J, Rascle N, Rayner H, Mapes D, Lopes AA, Fukuhara S, Akizawa T, Morgenstern H, Robinson BM, Pisoni RL, Combe C: The associations of social support and other psychosocial factors with mortality and quality of life in the dialysis outcomes and practice patterns study. Clin J Am Soc Nephrol 2011;6:142-152.

4 Kimmel PL: Psychosocial factors in dialysis patients. Kidney int 2001;59:1599-1613.

-5 Grzegorzewska AE, Izdebska A, Niepolski L, Warchoł W, Jagodziński PP: Self-Reported Physical Activity, Quality of Life, and Psychological Status in Relation to Plasma 25-Hydroxyvitamin D Concentration in Patients Treated with Hemodialysis. Kidney Blood Press Res 2016;41:886-900.

6 Sumanathissa M, De Silva VA, Hanwella R: Prevalence of major depressive episode among patients with pre-dialysis chronic kidney disease. Int J Psychiat Med 2011;41:47-56.

7 Kim HW, Choi-Kwon S: Structural equation modeling on quality of life in pre-dialysis patients with chronic kidney disease. J Korean Acad Nurs 2012;42:699-708.

8 Han SJ, Kim HW: Factors Related to Anxiety in Predialysis Patients with Chronic Kidney Disease. Int J BioSci Bio-Techno 2015;7:239-248.

-9 Palmer SM, Crewther SG, Carey LM, Team TSP: A Meta-Analysis of Changes in Brain Activity in Clinical Depression. Front HumNeurosci 2014;8:1045.

10 Price JL, Drevets WC: Neurocircuitry of mood disorders. Neuropsychopharmacology 2010;35:192-216.

11 Aouizerate B, Guehl D, Cuny E, Rougier A, Bioulac B, Tignol J, Burbaud P: Pathophysiology of obsessivecompulsive disorder: a necessary link between phenomenology, neuropsychology, imagery and physiology. Prog Neurobiol 2004;72:195-221.

12 Argyropoulos SV, Bell CJ, Nutt DJ: Brain function in social anxiety disorder. Psychiat Clin North Am 2001;24:707-722.

13 Atmaca M: What about the neuroimaging findings in social anxiety disorder? Rev Recent Clin Trials 2013;8:124-127.

14 Caouette JD, Guyer AE: Gaining Insight into Adolescent Vulnerability for Social Anxiety from Developmental Cognitive Neuroscience. Dev Cogn Neurosci 2014;8:65-76.

-15 Hunsaker MR, Fieldsted PM, Rosenberg JS, Kesner RP: Dissociating the roles of dorsal and ventral CA1 for the temporal processing of spatial locations, visual objects, and odors. Behav Neurosci 2008;122:643-650.

-16 Rogers JL, Hunsaker MR, Kesner RP: Effects of ventral and dorsal CA1 subregional lesions on trace fear conditioning. Neurobiol Learn Mem 2006;86:72-81.

17 Eliassen JC, Boespflug EL, Lamy M, Allendorfer J, Chu WJ, Szaflarski JP: Brain-Mapping Techniques for Evaluating Poststroke Recovery and Rehabilitation: A Review. Top Stroke Rehabil 2007;15:427-450.

18 Rae C: RE: Magnetic resonance spectroscopy of the brain: review of metabolites and clinical applications. Clini Radiol 2009;64:12-21.

19 Hasler G,van der Veen Jw, Tumonis T, Meyers N, Shen J, Drevets WC: Reduced prefrontal glutamate/ glutamine and gamma-aminobutyric acid levels in major depression determined using proton magnetic resonance spectroscopy. Arch Gen Psychiatry 2007;64:193-200.

20 Yildiz-Yesiloglu A, Ankerst DP: Review of $1 \mathrm{H}$ magnetic resonance spectroscopy findings in major depressive disorder: a meta-analysis. Psychiatry Res 2006;147:1-25. 


\section{Kidney \\ Blood Pressure Research}

-21 Bédard MJ, Chantal S: Brain magnetic resonance spectroscopy in obsessive-compulsive disorder: the importance of considering subclinical symptoms of anxiety and depression. Psychiatry Res 2011;192:4554.

22 Smith EA, Russell A, Lorch E, Banerjee SP, Rose M, Ivey J, Bhandari R, Moore GJ, Rosenberg DR: Increased medial thalamic choline found in pediatric patients with obsessive-compulsive disorder versus major depression or healthy control subjects: a magnetic resonance spectroscopy study. Biol Psychiatry 2003;54:1399-1405.

-23 Zung WW: A self-rating depression scale. Arch Gen Psychiatry 1965;12:63-70.

$\checkmark 24$ Lee YJ, Kim MS, Cho S, Kim SR: Association of depression and anxiety with reduced quality of life in patients with predialysis chronic kidney disease. Int J Clin Pract 2013;67: 363-368.

25 Stork C, Renshaw PF: Mitochondrial dysfunction in bipolar disorder: evidence from magnetic resonance spectroscopy research. Mol Psychiatry 2005;10:900-919.

26 Théberge J, Al-Semaan Y, Drost DJ, Malla AK, Neufeld RW, Bartha R, Manchanda R, Menon R, Densmore M, Schaefer B: Duration of untreated psychosis vs. N-acetylaspartate and choline in first episode schizophrenia: a ${ }^{1} \mathrm{H}$ magnetic resonance spectroscopy study at 4.0 Tesla. Psychiatry Res 2004;131:107-114.

27 Sung YH, Cho SC, Hwang J, Kim SJ, Kim H, Bae S, Kim N, Chang KH, Daniels M, Renshaw PF: Relationship between $\mathrm{N}$-acetyl-aspartate in gray and white matter of abstinent methamphetamine abusers and their history of drug abuse: a proton magnetic resonance spectroscopy study. Drug Alcohol Depend 2007;88:2835.

28 Hyder F, Patel AB, Gjedde A, Rothman DL, Behar KL, Shulman RG: Neuronal-glial glucose oxidation and glutamatergic-GABAergic function. J Cereb Blood Flow Metab 2006;26:865-877.

29 Rothman DL, Behar KL, Hyder F, Shulman RG: In vivo NMR studies of the glutamate neurotransmitter flux and neruenergetics: Implications for Brain Function. Annu Rev Physiol 2003;65:401-427.

- 30 Kantarci K, Jack Jr CR, Xu YC, Campeau NG, O’Brien PC, Smith GE, Ivnik RJ, Boeve BF, Kokmen E, Tangalos EG: Regional metabolic patterns in mild cognitive impairment and Alzheimer's disease: A ${ }^{1} \mathrm{H}$ MRS study. Neurology 2000;55:210-217.

-31 Kantarci K, Knopman D, Dickson D, Parisi J, Whitwell J, Weigand S: Alzheimer disease: postmortem neuropathologic correlates of antemortem ${ }^{1} \mathrm{H}$ MR spectroscopy metabolite measurements. Radiology 2008;248:210-220.

32 Morris MC, Evans DA, Tangney CC, Bienias JL, Wilson RS: Fish consumption and cognitive decline with age in a large community study. Arch Neurol 2005;62:1849.

33 Salthouse TA: When does age-related cognitive decline begin? Neurobiol Aging 2009;30:507-514.

34 Kadota T, Horinouchi T, Kuroda C: Development and aging of the cerebrum: assessment with proton MR spectroscopy. Am J Neuroradiol 2001;22:128-135.

- 35 Moffett JR, Ross B, Arun P, Madhavarao CN, Namboodiri MAA: N-Acetylaspartate in the CNS: From Neurodiagnostics to Neurobiology. Prog Neurobiol 2007;81:89-131.

-36 Baslow MH, Suckow RF, Gaynor K, Bhakoo KK, Marks N, Saito M, Saito M, Duff K, Matsuoka Y, Berg MJ: Brain damage results in down-regulation of $\mathrm{N}$-acetylaspartate as a neuronal osmolyte. Neuromolecular Med 2003;3:95-104.

-37 Onder G, Penninx BW, Cesari M, Bandinelli S, Lauretani F, Bartali B, Gori AM, Pahor M, Ferrucci L: Anemia is associated with depression in older adults: results from the InCHIANTI study. J Gerontol A Biol Med Sci 2005;60:1168-1172.

38 Moreno F, Sanzguajardo D, Lópezgómez JM, Jofre R, Valderrábano F: Increasing the hematocrit has a beneficial effect on quality of life and is safe in selected hemodialysis patients. Spanish Cooperative Renal Patients Quality of Life Study Group of the Spanish Society of Nephrology. J Am Soc Nephrol 2000;11:335342.

39 Mori K, Toda Y, Ito H, Mori T, Mori K, Goji A, Hashimoto H, Tani H, Miyazaki M, Harada M: Neuroimaging in autism spectrum disorders: ${ }^{1} \mathrm{H}-\mathrm{MRS}$ and NIRS study. J Med Invest 2015;62:29-36.

40 Gruber S, Frey R, Mlynárik V, Stadlbauer A, Heiden A, Kasper S, Kemp GJ, Moser E: Quantification of metabolic differences in the frontal brain of depressive patients and controls obtained by ${ }^{1} \mathrm{H}$-MRS at 3 Tesla. Invest Radiol 2003;38:403-408. 


\section{Kidney \\ Blood Pressure Research}

41 Järnum H, Eskildsen SF, Steffensen EG, Lundbye-Christensen S, Simonsen CW, Thomsen IS, Fründ ET, Théberge J, Larsson EM: Longitudinal MRI study of cortical thickness, perfusion, and metabolite levels in major depressive disorder. Acta Psychiatr Scand 2011;124:435-446.

$>42$ Howells FM, Hattingh CJ, Syal S, Breet E, Stein DJ, Lochner C: ${ }^{1} \mathrm{H}-$ magnetic resonance spectroscopy in social anxiety disorder. Prog Neuropsychopharmacol Biol Psychiatry 2015;58:97-104.

-43 Yamasue H, Fukui T, Fukuda R, Yamada H, Yamasaki S, Kuroki N, Abe O, Kasai K, Tsujii K, Iwanami A: ${ }^{1} \mathrm{H}$ MR spectroscopy and gray matter volume of the anterior cingulate cortex in schizophrenia. Neuroreport 2002;13:2133-2137.

-44 Kumar A, Thomas A, Lavretsky H, Yue K, Huda A, Curran J, Venkatraman T, Estanol L, Mintz J, Mega M: Frontal White Matter Biochemical Abnormalities in Late-Life Major Depression Detected With Proton Magnetic Resonance Spectroscopy. Am J Psychiatry 2002;159:630-636.

45 Henigsberg N, Bajs M, Hrabac P, Kalember P, Rados M, Rados M, Radonić E: Changes in brain metabolites measured with magnetic resonance spectroscopy in antidepressant responders with comorbid major depression and posttraumatic stress disorder. Coll Antropol 2011;35:145-148.

-46 Kaymak SU, Demir B, Oğuz KK, Sentürk S, Uluğ B: Antidepressant effect detected on proton magnetic resonance spectroscopy in drug-naïve female patients with first-episode major depression. Psychiatry Clin Neurosci 2009;63:350-356.

47 Taylor MJ, Godlewska BR, Norbury R, Selvaraj S, Near J, Cowen PJ: Early increase in marker of neuronal integrity with antidepressant treatment of major depression: 1H-magnetic resonance spectroscopy of $\mathrm{N}$-acetyl-aspartate. Int J Neuropsychopharmacol 2012;15:1541-1546.

$\checkmark 48$ Gonul AS, Kitis O, Ozan E, Akdeniz F, Eker C, Eker OD, Vahip S: The effect of antidepressant treatment on $\mathrm{N}$-acetyl aspartate levels of medial frontal cortex in drug-free depressed patients. Prog Neuropsychopharmacol Biol Psychiatry 2006;30:120-125. 